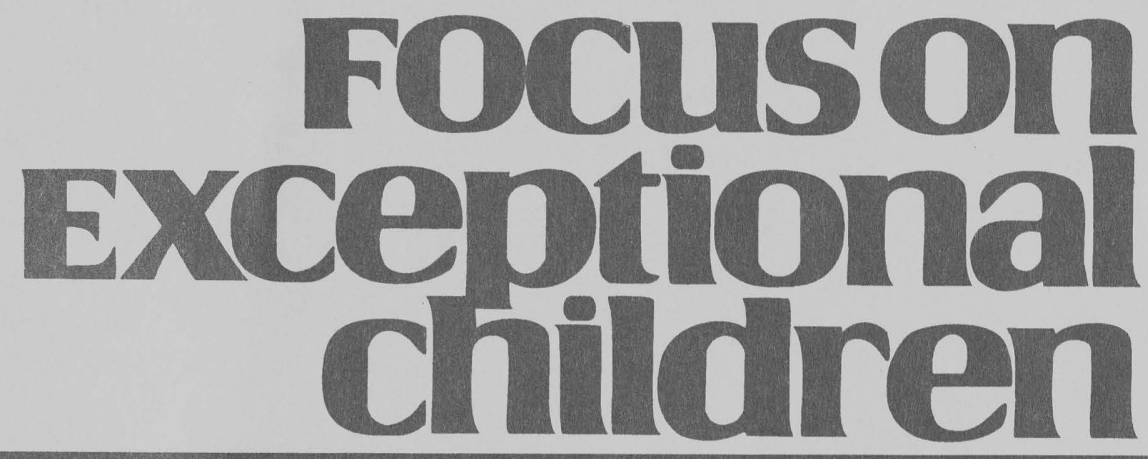

\title{
Teacher Education Reform Within University Special Education Programs
}

\author{
Regina Sapona, Jerry Etienne, Anne Bauer, Ann E. Fordon, Lawrence J. Johnson, \\ Martha Hendricks-Lee, and Nelson C. Vincent
}

Colleges and universities across the country are making efforts in teacher education reform in order to better the training of instructors and therefore the education of children. Our journey - to redesign our teacher education program in special education at the University of Cincinnati-began in 1985 with internal events (new faculty members, changes in department head) and external events (changes in our profession) resulting in a critical period of self-examination. After we began this process, the College of Education at the University of Cincinnati accepted an invitation to become a member of the Holmes Group. ${ }^{1}$ Membership in the Holmes Group committed all teacher education programs in the College of Education to a comprehensive reform agenda, with a central focus on urban education.

In previous years the college's connections with schools and teachers, and among ourselves as teacher educators, depended primarily on personal relationships initiated and sustained by faculty, and not on institutional and programmatic agreements. We now had an opportunity to pursue program reform efforts within a wider context (the entire College of Education) and to have an impact on teacher education programs beyond special education.

As we reviewed artifacts for this article (documents prepared for college administration, state certification review, NCATE reviews, and minutes from program meetings), we observed several phenomena that were key to changes in our program: learning to talk with one another, leaving the safety of our own group, and developing a special education core. As we shifted the focus of our teacher education efforts, we were able to articulate our program more carefully and work with other teacher education programs within the college as well as develop new relationships with teachers in the Professional Practice Schools (also known as Professional Development Schools). These changes were facilitated and supported by a collegewide reform effort now referred to as the Cincinnati Initiative for Teacher Education.

In this article then, we describe two aspects of interrelated changes in teacher education. We share various aspects of our journey through the reform process, while describing the influences of collegewide program reform and changes within teacher education on our thinking. Because the reform continues, we report on our work to date, the challenges we confronted, and our next steps.

This article is adapted from a chapter in Teacher Education in Transition: Collaborative Programs to Prepare General and Special Educators, edited by Linda P. Blanton, Cynthia C. Griffin, Judith A. Winn, and Marleen C. Pugach and published by Love Publishing Company. The contributors to this article were all affiliated with the University of Cincinnati when it was first published. 


\section{THE SPECIAL EDUCATION PROGRAM CONTEXT FOR REFORM}

A major challenge for the special education faculty was how to prepare teachers and other educational personnel to meet the needs of all children in the next millennium. Our practice had been successful with children in self-contained, isolated settings but would not meet diverse children's needs in settings such as general education classrooms. The faculty was charged to identify a vision within and across special education certification areas, and for services to children across the developmental contexts.

Prior to 1985 the Special Education Program consisted of 12 full-time faculty members, two part-time faculty members who shared appointments with other colleges in the university, and one faculty member who had a full-time appointment at the Cincinnati Center for Developmental Disorders teaching the equivalent of one course per quarter for special education. The Special Education Program was housed in the Department of Early Childhood and Special Education. Programs of study associated with Ohio certification areas were independent of each other and of other teacher education programs in the college: two undergraduate teacher education programs in the areas of multiple disabilities and developmental disabilities (the Ohio category

\section{Focuson
Exceptional children}

ISSN 0015-511X FOCUS ON EXCEPTIONAL CHILDREN (USPS 203-360) is published monthly except June, July, and August as a service to teachers, special educators, curriculum specialists, administrators, and those concerned with the special education of exceptional children. This publication is annotated and indexed by the ERIC Clearinghouse on Handicapped and Gifted Children for publication in the monthly Current Index to Journals in Education (CIJE) and the quarterly index, Exceptional Children Education Resources (ECER). The full text of Focus on Exceptional Children is also available in the electronic versions of the Education Index. It is also available in microfilm from Xerox University Microfilms, Ann Arbor, MI. Subscription rates: individual, \$36 per year; institutions, \$48 per year. Copyright (C) 2006, Love Publishing Company. All rights reserved. Reproduction in whole or part without written permission is prohibited. Printed in the United States of America. Periodical postage is paid at Denver, Colorado. POSTMASTER: Send address changes to:

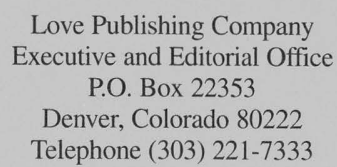

for mild mental retardation) and eight graduate programs in the areas of hearing impairment, specific learning disabilities, emotional/behavioral disorders, developmental disabilities, multiple disabilities, speech and language pathology, audiology, and administration and supervision in special education. A program in Early Childhood Special Education that had been attempted in 1975 subsequently was inactive and was just reemerging in 1985 .

Graduate students enrolled as master's degree students, or as post-baccalaureate students in the certification areas mentioned above, or as post-baccalaureate students seeking a validation or endorsement in Early Childhood Special Education. Each certification or validation area had separate methods courses and field experiences, with little collaboration among faculty members within special education. In addition to these programs, special education's contribution to the education of general education students was through two courses: an introductory course on individuals with disabilities and one course on mainstreaming.

During fall quarter 1985, a core group of faculty members in the Special Education Program volunteered to serve as members of a program development committee. This group developed a faculty survey to identify the goals of the existing programs and the issues related to these goals. A focused follow-up survey was distributed, and this was used to develop a concept paper describing a framework for the program to use as a guide for future work.

By fall 1986, faculty members had reached consensus on the framework and a plan to develop a special education methodology core that would serve all special education teacher education programs. Also in this concept paper we identified a core of knowledge and experiences we believed to be unique to special education. This core was intended for all graduate students in special education (not only those interested in pursuing certification) and would be shared across all disability areas. In addition, we expressed interest in beginning formal collaborative activities with faculty members in elementary and secondary education programs and strengthening the existing collaboration with the early childhood education program.

Our conceptual model, to be used for future program development, referred to

- the dynamics of the learner, indicating a strong developmental perspective;

- the dynamics of the profession, referring to pedagogical knowledge; and

- the dynamics of the field, indicating an emphasis on the public school-aged population identified as having disabilities.

This model was used to generate new programs of study based on a unified special education core of knowledge and also was used in response to a state certification program review that took place in February of 1987. 


\section{THE COLLEGEWIDE CONTEXT FOR REFORM}

At about the same time that we shared our model publicly, the College of Education Holmes Planning Task Force presented a design process to guide collegewide reform efforts. The strategy was to build consensus around principles that would guide planning. In so doing, faculty members would learn to work together rather than to begin this process by debating educational theory, practices, or curricula. For the design process the task force borrowed heavily from an experiment in architecture at the University of Oregon. Frustrated that their master plans for campus building and development became obsolete before it was enacted, the University of Oregon, led by architect Christopher Alexander, developed an alternative process that was sensitive to changing conditions and responsive to the needs and experiences of the people who used the facility (Alexander, Silverstein, Shlomo, Ishikawa, \& Abrams, 1975). The task force revised the initial principles to guide change within the College of Education at the University of Cincinnati (1987). The six planning principles that emerged are as follows:

1. The principle of patterns: All design and implementation will be guided by communally developed and adopted teaching and learning frameworks called "patterns." Collegewide deliberations will determine a set of patterns to embody the missions, goals, and primary means by which teachers would be educated in the College of Education at the University of Cincinnati. These central patterns will frame all curricula and pedagogy and become criteria by which program effectiveness will be judged.

2. The principle of organic order and change: Planning and implementation will be guided by a process that allows the whole to emerge gradually from local acts. Rather than imposing a master plan on the college, the nature of teacher education at the University of Cincinnati will emerge progressively and responsively from the design work of faculty and students in local program areas.

3. The principle of local decision making: Decisions about what to do and how to do it will be initiated and made by members of the community who are most affected. Not only will design work be focused locally, but decision making about program form and content will be localized in the faculty, students, and school collaborators who are closest to the work of educating teachers.

4. The principle of individual program growth: The design undertaken in each evaluation/implementation period will be weighted overwhelmingly toward local program areas. All programs will not be expected to change in the same ways at the same pace. Growth and change will be weighted most heavily toward local projects rather than toward collegewide initiatives. This process is expected to provide the freedom for faculty to explore alternative ways of defining programs and program responsibility.

5. The principle of evaluation: The well-being of the whole will be protected by a biennial evaluation detailing which program area activities are working and which are not, based on the patterns adopted by the community. The focus of the evaluation work will be to provide an opportunity for local participants to examine the effectiveness of program activities and experiences and the extent to which they are aligned with program and college goals.

6. The principle of coordination: The deliberate emergence of organic order in the whole will be assured by an open process that assesses current program status and regulates proposed program changes. A process open to the college and university communities will be established to coordinate the local work of educational programs according to the core set of patterns and to provide a means by which patterns may be modified or added.

Even though all of the principles must be present for the process to succeed, the principle of local decision making was paramount. "Local" first was defined by programs-for example, the Elementary Education Local Group and the Secondary Education Local Group. Later, as more areas in the college made contributions to teacher education, other local groups, such as the Educational Studies Local Group and the Student Support Services Local Group, emerged. The Special Education Program had worked for a year on redesigning programs when the collegewide reform activities started and, fortuitously, the principle of local decision making guaranteed that our efforts would continue in ways that respected the primacy of local programs.

The principle of the patterns is a complicated and unique approach to ensuring consistency and flexibility across programs. To safeguard against merely repackaging existing teacher education programs, the college asked a basic question: How might we best describe the knowledge and skill of the experienced practitioner? Rather than responding to this question with a list of isolated features, the structure and function of the pattern language provided us with a means to envision what our programs could be. Language has an explicit framework with individual components that are interactive and generative. Whereas Christopher Alexander's architectural pattern language is one of design (Alexander, Ishikawa, \& Silverstein, 1977), a pattern language for teaching is one of both design and performance.

As a planning principle, the pattern language concept allowed us to deliberate in a nonthreatening way on the theoretical and practical matters of teaching and learning. Everyone was encouraged to submit ideas for patterns. Just as a language develops with new experiences, the pattern language has grown and changed. The current (Yinger, 
1992) version, A Pattern Language for Teaching, has 89 patterns, organized into three levels:

1. College Core Patterns, with 10 patterns (for example: multicultural focus, individual diversity, and urban mission) that embody our most important values; these should infuse everything we do

2. Outcome Patterns, addressing outcome patterns in three areas: Professional Ways of Knowing (such as knowledge of content, knowledge of self), Professional Ways of Doing (such as planning instruction, discussions, collaboration), and Professional Ways of Being (such as commitment to each student, personal development orientation)

3. Professional Study Patterns, addressing outcome patterns in two main areas-Professional Study Patterns and Professional Practice Patterns - both of which are subdivided into Knowledge-Related Activities and Knowledge-Related Structures

Each pattern follows the same general format: a rationale (based on the nature of teaching practice, professional needs, theory and research, and college goals); a prescriptive statement (which acts as a general guideline for pattern enactment in each of the teacher education programs); a list of essential pattern indicators (describing specific activities that would provide evidence for the existence of the patternin-use); and a statement of the pattern's relationship to other patterns in the language (patterns connect in network-like fashion to represent complex activities). For example, the pattern Knowledge of Contexts begins with a rationale for using a constructivist approach:

\begin{abstract}
The contextual basis for learning, understanding, and practice should be a central theme in each teacher education program. Students should study various contexts, their general characteristics, and their manifestation in particular teaching situations. Practical experience should be afforded in a variety of contextual configurations.
\end{abstract}

This statement is followed by a listing of essential pattern indicators (such as "case studies of contextual configurations influence local classrooms; working with teachers successful in urban contexts") and the relationship to other patterns (for example, Multicultural Focus, Urban Mission).

The pattern language has been accepted as part of our NCATE knowledge base. Each newly developed course in the redesigned programs arises out of a selection of patterns. Rather than using syllabi to represent our courses, we use portfolios in which all outcomes, readings, activities, assignments, and evaluation techniques are connected explicitly to the pattern language. When course portfolios are submitted for initial approval, they typically include information distributed to students, such as expectations for specific assignments, readings, and possible agendas for class meetings. Portfolios also include information on how that particular course or experience fits within an overall program of study and how the course content is integrated across other courses or experiences.

As courses are offered in future years or by different faculty, the initial course portfolio is modified or adjusted based on feedback from students and teachers in the Professional Practice Schools. Consequently, we are assured that every teacher education program meets the collegewide vision and that each program has the freedom to address values, skills, and dispositions in ways that the respective program faculty sees fit.

\section{REFORM EFFORTS WITHIN SPECIAL EDUCATION}

The use of the pattern language and design principles provided the context within the College of Education to support local groups as they tackled the challenge of program reform. Two events seemed to contribute to the development of a special education core and areas of emphasis. Through use of the pattern language, Special Education Program faculty members learned to talk with one another about our beliefs. As we discussed our ideas with faculty members outside our program, we began to clarify our beliefs. The special education faculty also developed a sense of community as we shared our frustrations and successful discussions with faculty members outside our program. This allowed us to become more comfortable with confronting the tough questions and decisions our program faculty needed to make.

\section{Learning to Talk With One Another}

After years of maintaining separate programs of study, how do faculty members begin a dialogue about core beliefs? As mentioned earlier, the program faculty developed the concept paper describing core knowledge and experiences we believed to be unique to special education. Still, we had still been unable to agree on adopting a core of coursework for all graduate students entering our master's in education program. This may have occurred because of lack of time and commitment to examining shared beliefs. Four faculty members in the program who worked with graduate students piloted integrated coursework, but others within the program were unwilling to surrender control and maintained separate courses. Faculty members who were engaged in teaching both graduate and undergraduate programs did not have the time to experiment with their programs of study.

One model being proposed worked well at the graduate level because most graduate faculty members had developed shared beliefs about teaching and learning through their piloting efforts. Similar modifications to the undergraduate programs were much more difficult because of dissimilar beliefs, strong feelings of ownership of specific courses, and heavy instructional responsibilities that did not allow time to develop programmatic changes. Further, because the certification areas of developmental disabilities and multiple 
disabilities were offered at both levels, changing only the graduate preparation program would have been awkward.

Despite the constraints, faculty members in special education began to learn about each other's visions and the changes that had to occur in special education to accomplish those visions. The first step was to learn to talk with one another, and our vehicle for beginning these discussions was the pattern language.

The problems of ownership of specific courses and varying commitment to the development of a shared vision seemed overwhelming. In keeping with the principle of local decision making within our collegewide design process, special education faculty members had become members of the Special Education Local Group. The faculty participated in bimonthly special education program meetings to discuss the day-to-day operations of our program (e.g., admissions, scholarship awards, class orders, graduation lists) and bimonthly Special Education Local Group meetings to engage in dialogue to redesign our program using the pattern language. The Local Group meetings were facilitated by a member of the Educational Administration Program. This faculty member helped set agendas and ensured participation and engagement by all special education program faculty members.

Using the pattern language freed us from the jargon unique to the field of special education and provided us with a shared language, both within our program and across other programs and departments. The pattern language was unfamiliar and new for most faculty members. We were engaged in examining particular patterns to make our own meanings explicit to one another when a key event occurred in November 1988, related to the pattern of respect for diversity. Our department head requested that each faculty member bring a one-page response, interpretation, or definition of the respect for diversity pattern to the next local group meeting. For some of us, sharing our most basic beliefs was particularly difficult. Over the course of several intense discussions, we learned about one another's views and participated in conversations that led eventually to refinement and redefinition of the shared philosophy of our program.

Our previously published philosophy had not required us to examine critically how we were preparing teachers with respect to diversity of all learners and, more specifically, individuals with disabilities. This philosophy had become comfortable, and it no longer challenged us. The recognition that we were not challenging ourselves to ask new questions about meeting individual needs led to development of the guiding principles given below:

- Individuals with disabilities should be viewed as learners who demonstrate variations in development. This implies that teachers need to understand typical development as well as the impact of various conditions on learning, and to recognize that all individuals have a right to participate in the community of learners.

- Special education graduates must be prepared for the future. We anticipate that special education and general education teachers will be expected to fulfill a variety of roles and positions in educational settings and agencies that are very different from current roles. Teachers also will be expected to collaborate routinely with one another in the years ahead. The forms of this collaboration and the types of roles teachers assume will, by necessity, be fluid and will be developed over time to meet the needs of a wide variety of learners.

- The program will be committed to the inclusion of all learners (inclusive education) in educational settings. This orientation will emphasize excellence in teaching, integrated programs, and an exploration of alternative program delivery systems (in contrast to the current separation of special and general education students and categorical programming).

These new principles required us to make dramatic changes to our program. Based on our belief that special education teachers need to have an understanding of typical development and experience with typical learners, on January 6, 1989, the Special Education Local Group voted to discontinue undergraduate certification programs in special education and eliminated two program options at the undergraduate level (Ohio certification in developmental disabilities and multiple disabilities). A major factor in reaching this decision was the increased demand for special educators to work in general education settings, requiring an understanding of both general and special education. As the undergraduate major was phased out, the special education faculty became more involved in working collaboratively with faculties in the early childhood, elementary, secondary education, and educational foundations programs to ensure that all preservice students would be better prepared to meet the needs of all learners.

\section{Leaving the Safety of Our Own Group}

Deciding on our own destinations for this journey was difficult enough, let alone discovering the multiple ways we could travel and work together. Our journey also was influenced by expeditions with colleagues outside our program. These sometimes turned into side trips, just as rigorous and stressful as the journeys within our own group, with relative strangers that taught us many things about one another.

As the special education faculty continued its own reform work, the Holmes Planning Task Force raised issues that cut across all programs. Through that task force, committees were created to address various issues: Professional Practice School Committee, General and Educational Studies Committee, and Admissions and Advising Committee. In those committees special education faculty members regularly represented our concerns about educating teachers to work with all learners including those with disabilities. For example, our contributions to the Educational Studies Committee, which later became a local group, led to development of a 
course entitled Individual Diversity, now part of all undergraduate teacher education programs with the college.

After articulating our vision and guiding principles in 1989 , special education faculty members volunteered to serve as representatives to other local groups. As representatives, we contributed to development of the teacher education programs in early childhood, elementary and secondary education. Our intent was to help integrate ideas related to special-needs learners into those programs of study rather than to view topics associated with special education as addons. For example, course portfolios developed for the secondary education program include topics such as "accommodations for individuals with diverse needs." We also had faculty representatives on a local group that emerged laterthe Student Support Services Local Group. This group designed experiences to enable all preservice teachers to work collaboratively in teams (with school psychologists, counselors, nurses, work-study coordinators, administrators, and personnel from nonschool agencies) to meet the needs, not just the "labels," of all learners in schools.

Special education faculty members met with varying degrees of success in attempting to participate in the conversations taking place in the other local groups. During the early stages of development, the Holmes Task Force held large-group meetings, referred to as Friday Forums, to which all teacher education faculty members were invited. These meetings centered on issues such as resolving internal programmatic concerns, working with the arts and science faculty, developing relationships with public school faculties, refining the process of teacher preparation, and working with Professional Practice Schools.

Often, dialogues among faculty members across programs illustrated our differing beliefs about learning and teaching. We were pleased by the many shared beliefs that emerged as we worked together. Some tenured faculty members expressed their amazement that conversations with colleagues across programs were occurring; other more recently hired faculty members were excited about the possibilities these conversations would yield. In these large-group discussions there were no balkanized program boundaries. We were all learning how to use the pattern language to design our programs; it gave us a common place to begin dialogue, and through its use we were learning how to share ideas across programs.

During an April 1989 meeting of the Special Education and Elementary Education local groups, some long-time faculty members commented that this was the first time in over 20 years that open and collaborative discussions had taken place across program areas. Examples from the minutes of this meeting illustrate this collaboration: "potential courses special education can offer," "help in course development," "work together on ways to adapt instruction to a range of learner needs," "conduct seminars in special education concerns," "serve as members of a teaching team," and "participate in various internship experiences . . . during fourth and fifth years as members of faculty cohorts."
As faculties across local groups engaged in discussions around the pattern language, we all began to develop our ideas for reform more clearly. As we left the safety of our own local group to serve as representatives to other local groups, we met with success and also encountered obstacles and dilemmas, which we shared informally and during our regularly scheduled local group meetings. Thus, two processes occurred simultaneously:

1. Discussions across local groups helped special education faculty clarify our ideas.

2. Discussions within our own local group led to the development of a sense of community and trust in one another.

The emergence of trust and comfort in sharing ideas was necessary to development of a cohesive special education core. We also needed to be very clear about our shared beliefs as we became aware of our potential to influence or participate in the education of all teachers in the collegegeneral and special education alike.

\section{A Program Shift: Developing a Special Education Core and Areas of Emphasis}

Despite the participation of special education faculty members as collaborative partners in general teacher education reform issues, we each were still associated with a categorical preparation program. Faculty members taught classes, advised, and supervised teacher education students separately in the identified Ohio areas of developmental handicaps, multiple handicaps, hearing impairment, specific learning disabilities, severe behavior handicaps, speech and language pathology, audiology, and administration and supervision in special education. Clearly, we had to move away from this categorical orientation and move forward to developing a common core of courses that all special education students would take, whether they were interested in certification or were pursuing a master's degree without certification.

\section{Developing a Special Education Core}

Most of our special education programs offered separate courses (e.g., methodology courses, field experiences), and faculty members associated with different disability categories seemed to share few philosophical beliefs. This situation arose during a period of some 10 years in which the special education program faculty rarely met more than once a year. The absence of frequent communication led to fragmenting of the program into individual efforts. The years from 1985 to 1989 were utilized to reestablish lines of communication and to build trust across all programs within special education. We thought that building relationships across program lines would be extremely difficult unless we trusted one another.

The special education faculty revisited the conceptual model and competencies developed in 1985 that describe the dynamics of the learner, professional knowledge, research, 
communication/consultation, and assessment. Much of the discussion centered on the need to build a common field of knowledge that would provide the basics for meeting the needs of all learners. We debated how far this commonality existed, if at all, and with whom it existed. We negotiated the content areas and reviewed publications that supported or detracted from the notion of a common field of knowledge.

During this time we developed an initial version of our graduate program in special education that included several course sequences. This was published first in January 1989 when we proposed to the Holmes Task Force how our program might look under the Holmes Initiative Program guidelines. A review of this first document indicated that we had retained categorical programs of study. An external review team highlighted the faculty's overall efforts to date to ensure that all students would receive quality education across all the programs involved in teacher preparation. The review team also mentioned that the faculty needed to address the "separateness" within special education - that is, the separate programs of study. The reviewers also seemed to believe that this separateness was a "work in progress" and that this could be resolved at a later date.

Not until October 1991 did we revisit the strategy we had utilized originally as we discussed the pattern of respect for diversity. All special education faculty members were asked to develop a one-page description of "shared content" or knowledge that was common to all our programs of study. Until this time we had been afraid to ask this question about shared beliefs, as we had become comfortable with distinct programs based on various conceptions of teaching and learning; we were literally afraid of the conflicts that might arise if we were to confront our differences. We had developed enough trust in the course of this multi-year process, however, to move the program development to the next level.

A small group of faculty members reviewed the ideas about "shared content" that everyone submitted and then grouped these into pattern language categories: professional ways of knowing, professional ways of being, professional ways of doing. We shared our work with special education faculty members, who then made modifications and finally achieved a consensus about what shared content had been produced. By November 13, 1991, we had drafted these ideas into a series of thematic statements. With minor revisions, the following themes were endorsed by all faculty members in special education:

- Knowledge of human growth and development including learning theories and principles, and of variations in development, is essential in supporting the learning process.

- Recognition of the role of communication/language development and cognitive development in its broadest sense provides insight into the learner's behavior, interaction, and learning.

- Acknowledging and valuing the individual diversity, culture, ethnicity, and gender of each learner contributes to the development of all individuals involved.

- An understanding of our history (where we have been) and where we are currently (in terms of addressing individual diversity) supports the process of ongoing development (where we are going) so we will be prepared in the future to meet learners' needs.

- Knowledge of political, research, legal, professional, community, and ethical contexts in which services for learners who vary from their peers are developed, implemented, and evaluated is necessary/essential.

- The special educator is a lifelong collaborative colearner who communicates with colleagues, parents, community members, other professionals, and learners through the perspective (or from the viewpoint) of understanding families, cultural and ethnic perspectives, and community influences.

- The special educator supports each individual's learning and development through an ongoing process of assessment, generating curricula specific to the information that emerges, and evaluating not to judge the learner but, rather, the process in which the learner and teacher have been engaged.

- Advocacy for learners, families, and teachers directs (drives) our interactions within the field.

- Teaching is research; it is ongoing RE-searching and reflection to discover how to best facilitate learning for each student and community of learners.

- Teachers should assume an inclusionary, proactive stance in facilitating the development of all learners with whom they interact.

- Teachers are questioners who, conjointly with parents, colleagues, community members, and learners, strive continuously to engage in professional best practices and seek effective and innovative alternatives in addressing issues and concerns.

- As professionals, we are engaged in modeling and supporting our students in behaving as ethical and responsible individuals, with a strong sense of social justice and an interest in contributing to others' well-being.

These themes were developed into four core seminars: Human Development and Diversity of the Challenging Learner, Educator as a Collaborative Co-Learner, Teaching as Reflective Practice, and Designing Learning Environments for the Challenging Learner. Because we had no interest in duplicating the emphasis on human development in the College of Education master's degree core, only four core seminars central to special education were necessary. Work groups drafted course portfolios for these four core seminars.

To introduce our thematic statements, our program documents include references to a major long-term disciplinary trend that has guided our program development and implementation efforts. We believe all children develop within a series of nested contexts (Bronfenbrenner, 1977; Kurdek, 
1981). This recognition of the diverse developmental contexts of all learners is reflected in the following theoretical beliefs:

- All development occurs within a personal context, which is unique for each individual. The personal context is a complex interaction of interpersonal, community, and societal relationships.

- Development is transactional; each response has an impact on the subsequent responses of the individuals in the context in which they are interacting.

- Children learn from a variety of "teachers."

- Children vary in their developmental rates and learning styles, in their ways of accessing the environment, and in their interactions and communication with others.

In addition to developing themes and a common vision, the faculty also agreed later on the development of a threequarter methodology sequence beginning with the core seminar entitled Designing Responsive Learning Environments for the Challenging Learner. This sequence is intended to present information and engage graduate students in inquiry in general areas of literacy development. Students enroll concurrently in professional seminars associated with specific disability areas. If the topics in the methodology sequence involve the design and implementation of Writer's Workshop, for example, the discussion in the professional seminar might include specific considerations or modifications needed when implementing a workshop format with learners identified as having learning disabilities or behavior disorders. Because certifications in Ohio have a range of kindergarten through grade 12 , students interested in early childhood special education enroll in their own methodology sequence and professional seminars.

\section{Developing Areas of Emphasis}

As we worked on the Special Education Program Core, we also had to make decisions about which certifications we would offer and which we would not because of limitations in resources. Eventually we settled on areas restricted to school-age learners who had been identified as having a disability (with associated certifications).

After integrating our programs of study and eliminating the two undergraduate teacher certification areas, the Special Education Local Group developed one master's degree program with various program-of-study options. Four of the five options, or areas of concentration, lead to teaching certificates (in Developmental Handicaps, Hearing Impairment, Multiple Handicaps, Several Behavior Handicaps, Specific Disabilities) or a validation (Early Childhood Special Education), added onto an initial teaching certificate. Students interested in working on a specific teaching certificate or validation work with an advisor to select an area of concentration that most lends itself to earning the teaching certification, or validation most representative of their area of interest. The specific areas of concentration associated with specific certification or validation program options follow:

1. Classroom Structures and Behavior Management: selected by graduate students seeking Ohio certification in Severe Behavior Handicaps and Specific Learning Disabilities

2. Educational Alternatives for Individuals With Significant Challenges to Learning: selected by graduate students pursuing Ohio certification in Developmental and Multiple Handicaps

3. Language and Communication: selected by graduate students pursuing Ohio certification in Hearing Impairment

4. Working With Young Children and Families: selected by graduate students pursuing Ohio validation in Early Childhood Special Education

A fifth program-of-study option was developed to meet the needs of individuals pursuing a master's degree only (those who are not interested in seeking a teaching certificate or validation). This individually designed area of concentration is designed with guidance by, and approval of, a faculty committee.

\section{Feedback From the Field and Other Groups}

As we worked through the design process for the Special Education Program Core and program structures, we sought feedback from teachers in the field and other professionals. We received support and funding from the college to hold two large group meetings: a teacher consultation meeting (January 1992) and an administrators/supervisors meeting (March 1992). The Teacher Education Council, a group of faculty members from across the college, administrators, and representatives from the public schools, reviewed an April 1992 program version to look for evidence of pattern language and to examine how well the Special Education Program met the tenets of the Cincinnati Initiative for Teacher Education-a name change from the Holmes Initiative to indicate progress and ownership of the new preparation programs.

Many program documents were developed as we underwent review from other groups within the college, the university, and external agencies such as the Council for Exceptional Children and NCATE. With each new audience we tried to specify how we were going to actualize the feeling of responsibility we had for educating all learners. Various reviews described our program as forward thinking and as having a strong thematic and theoretical basis.

\section{SPECIAL EDUCATION CONTRIBUTIONS TO COLLEGEWIDE UNDERGRADUATE TEACHER EDUCATION}

Though the Special Education Program phased out its two undergraduate teacher education programs, faculty members believed that all education majors should be prepared to 
work with learners who have special needs. This led to a strong commitment to the education of undergraduates in the early childhood education, elementary education, and secondary education programs. Our influence and participation in these general education programs currently takes two forms: direct participation in providing instruction and ongoing work with Professional Practice Schools.

\section{Providing Instruction to Undergraduates at Various Levels}

The Special Education Program faculty's goal was to become a presence in all levels of undergraduate teacher education, starting with the very first experience students have in the College of Education. One of the first patterns to be identified in the pattern language was Linking Seminar. Linking Seminars were designed as one-credit-hour education courses offered in the students' first and second years. Linking Seminar was designed to explore the relationship between the teacher and the school, and the students and the community, in regard to present and future goals and objectives.

A seminar designed to help undergraduates link their Arts and Science degree majors and their initial work as students preparing to become teachers allowed college faculty to build consensus about the requirements for the Arts and Sciences degree. The Linking Seminar guaranteed that students would interact with College of Education faculty, and that they still would be "our" students, even though most of their early years in the program were spent in the College of Arts and Sciences. Special Education. Program faculty members have designed and taught Linking Seminars for 4 years, and they continue to add their voices and influence to the topics presented in this seminar.

The Special Education Program faculty also participated in developing a series of coordinated seminars that occur in the third, fourth, and fifth years of the Cincinnati Initiative undergraduate preparation programs. A local group referred to as Educational Studies was created to address three areas: learning and development, human diversity, and culture and schooling. Faculty members in special education and educational foundations formed cohorts to design and implement six coordinated seminars: human learning, individual development, individual diversity, language and communication, assessment and evaluation, and social inequalities and schooling, as well as Linking Seminars. The Coordinated Seminars, so named because they were to be coordinated with other components of an undergraduate preparation program, were intended to provide information on specific content areas such as language and communication or development.

For example, elementary education undergraduate students enrolled in the Language and Communication seminar were expected to also enroll in coursework in literacy learning and the study of children's literature in addition to their work as interns in a Professional Practice School. Ideally, the faculties associated with those courses and experiences would work together to provide an integrated experience (developing shared assignments, for example).

Some of these seminars are in the first year of implementation. Others have been offered the past 4 years. Coordination among faculty and across various programs has been a new experience for many faculty members.

During the fifth year of study, special education faculty members participate in a seminar known as Student Support Services. This seminar is integrated with the fifth year internships and was developed by the Student Support Services Local Group. It is designed to provide content knowledge in topics such as referral for additional support, referral for possible identification of disability, and knowledge of the array of services required by law and by need in order for a child with a disability to function within a group of peers. Students also are exposed to the range of factors that impinge upon quality education for all students.

\section{Working With Professional Practice Schools}

The special education faculty has made significant contributions to the development of new ways of working with the public schools. Although individual faculty members had developed strong relationships with specific teachers in local school districts, the college-in partnership with the Cincinnati Public Schools and the Cincinnati Federation of Teachers-worked together to create a system of Professional Practice Schools. Professional Practice Schools have three interrelated goals (American Federation of Teachers, 1988):

1. To support student success

2. To provide professional education and professional induction programs for teacher education students and for beginning and experienced teachers

3. To support systematic inquiry directed toward the improvement of practice

The Cincinnati Public Schools are well known for their innovations, including those in the area of professional development of teachers. Teachers and administrators in Cincinnati have created a career ladder, as well as a peer evaluation and assistance program. These recent achievements in collaboration helped to ease the functioning of a joint planning committee consisting of five members each from the school district, the union, and the university. The joint planning committee created guidelines for design and asked individual schools for proposals to become Professional Practice Schools. Schools were selected, and a pilot program was started.

The relationship with the Professional Practice Schools was clarified in 1992. The responsibilities of the team of professional practitioners were expanded to include a full partnership between the university and the public school faculties. This partnership was solidified through a series of meetings that began in 1993 and has continued since then. Teams of faculty members in the Professional Practice 
Schools worked collaboratively with campus-based faculty members to design innovative ways of working together.

Pilot efforts in the 1994-95 academic year with special education graduate students serving as interns in two Professional Practice Schools were highly successful. Special education graduate students now are working as interns who assume half-time teaching responsibilities in six Professional Practice Schools. Campus-based special education faculty members serve as liaisons to the schools through their participation as members of teams that mentor interns. In addition, special education faculty and school faculty members work together regularly to gain insight into educating all children, to assist the schools in educational change activities, to encourage the school faculty to become more inclusive in its practices, to engage in professional development activities, to model teaching practices and, most important, to learn from faculty members who are implementing theory and providing the daily guidance necessary for our special education interns to become quality teachers. This sharing of expertise is modeled in a setting where respect and effort are expected and evident from both groups of faculty in each of the teams.

\section{FUTURE CHALLENGES: WHERE DO WE GO FROM HERE?}

As we examine the artifacts and reflect on our journey to date, we are amazed at how far we have come and how much we have learned about one another. The journey has been rugged, with detours and many new traveling companions. We are revising and fine-tuning our program constantly as well as learning to communicate better where we want to go and how to get there. We are examining emerging concerns: development of the pattern of faculty cohort, changes in state certification requirements, fidelity to program themes, linkages to Professional Practice Schools, and program evaluation.

We currently are immersed in our third year of implementation for the Special Education Cincinnati Initiative for Teacher Education program. The other local groups in the college are offering for the first time fifth-year courses and internships in the Professional Practice Schools. Though the challenges we face are not as dramatic as our initial need to integrate our programs, they are critical to the ongoing success of our redesign efforts.

\section{Working Together: \\ Fine-Tuning the Pattern of Faculty Cohort}

One challenge faced during pilot efforts was the linking of internship requirements with coursework requirements. Communication has been a constant challenge, and we have targeted this for specific attention. Special education faculty members currently are meeting regularly with teachers who serve as mentors to our interns in the Professional Practice Schools as well as representatives from other local groups.
We are trying to define what is meant by the pattern of Faculty Cohort and how we can implement a team approach to mentoring interns. Special Education Program faculty members are assigned as liaisons to specific Professional Practice Schools and have tailored their roles to the specific needs of their school, ranging from helping teachers initiate discussions on inclusionary practices to providing support for interns who work in inclusionary settings. This cohort also attempts to ensure the integration of course requirements with internship responsibilities in the Professional Practice Schools.

\section{Certification Issues}

Our basic program of study was designed for individuals who enter our graduate program with a teaching certification. Our challenge now is to develop program modifications needed for graduate students who enter our program with backgrounds other than in teacher education. This is particularly important given the likelihood of changes in state certification requirements.

\section{Initial Certification Requirements}

In the past a number of highly qualified graduate students have completed our program without a prior background in education-for example, social workers and students with degrees in psychology, economics, or journalism. Given that one of our guiding principles has been "experience and background in general education," and given that changes in state certification standards will require special education teachers to have a general education certificate, certification programs that provide initial certificates in early childhood, elementary, and secondary clearly will best allow talented graduate students from diverse backgrounds to prepare to enter special education. We are in the initial stages of discussion of a blended teacher preparation program for graduate students who would like to enter the field of special education from backgrounds other than general education.

We are, in essence, redefining the culture of teacher preparation and redefining the population from which teachers are being prepared at the University of Cincinnati. We are asking the early childhood, elementary, and secondary education programs to accept the responsibility for teaching all children, including those with variations (whether identified as having a disability or not) and to share coursework with students in special education. This is a major paradigm shift that will require time to actualize.

\section{Changes in State Certification Requirements}

Changes in state certification programs will continue to impact our work. Though we acknowledge that we believe we are preparing teachers for a wider audience than the State of Ohio, we are a major state university. Consequently, we must ensure that our graduates fulfill state licensure standards. This regulatory provision requires continuous reexamination of how our experiences are implemented and how 
we set priorities for program reform. Although the pattern language, the philosophical positions taken by the faculty, the relationships with other programs and with the Professional Practice Schools provide us with a well grounded starting point for continuous program reform, we do anticipate that ongoing program modifications also will be based on our response to new state requirements.

We will continue to revise our program as we improve working with one another both within the college and in the Professional Practice Schools. Although we may have to modify the delivery of experiences to preservice students, we believe the program can sustain the delivery of high quality teacher preparation to all students.

\section{Fidelity to Program Themes}

Fidelity to our themes is a constant source of concern. Some faculty members are reluctant travelers on our journey, for a variety of reasons. Our intent was that the themes would be infused throughout all courses, yet we realize we must not infringe upon any individual faculty member's academic freedom. Revisiting or reaffirming our themes, coteaching, and team teaching should provide strategies for maintaining our fidelity without using coercive or subversive methods. Faculty development is a key to the issue of fidelity. This has been achieved by building understanding and consensus in all discussions during meetings and as we share information about our successes and challenges in working with other faculty across the college and in the Professional Practice Schools.

We also need to look at innovative means of providing faculty with the time and resources to explore different ways of preparing teachers. We need to find the means of providing "real" rewards for these efforts. For example, this past year the division head offered relief from one class per year for each faculty member who was a member of a school planning committee in the Professional Practice Schools. This was a major breakthrough because it provided tangible evidence that the effort is considered important. The College of Education's Research and Development Office also has awarded small grants that allow faculty members to study their own teaching with the goal of improving our own practice.

\section{Linkages to Professional Practice Schools}

Establishing linkages to Professional Practice Schools requires time for those of us at the college and for those in the schools to learn about one another. Some of us are serving as liaisons to schools in which we have little familiarity with the local neighborhood communities. Some of the Professional Practice School teachers who assist us with our efforts to integrate internship and course requirements have had little experience in serving as partners in the teacher preparation process. We are engaged in discussions leading to the development of a common philosophy and the development of inclusionary practices in the schools. We have worked and continue to work to restructure our relationships to dispel myths of "ivory towerism" from the university and "a lack of concern for theory" in the schools. Equal responsibility and equal involvement are the intended reality.

Redefining the culture of teacher preparation requires immense dedication and investment of time. We find ourselves working against the tendency to become jaded and the associated danger of losing sight of our vision. This applies to both faculties, those in the Special Education Program and those in Professional Practice Schools. Both institutions are limited in the numbers of faculty members available and resources. Over the next few years the faculty cohorts will work to resolve some of these problems by sharing coursework, mentoring, program development, and professional development. If our experiences with program reform hold true, this model of sharing should provide the richness of outcomes necessary to soften the burdens of time and effort inherent in program reform.

\section{Evaluation}

The special education faculty has adopted a 4-pronged approach to assist us in evaluating our program reform efforts:

1. We evaluate individual courses through student evaluations completed anonymously at the end of each quarter.

2. We have established a cohort group consisting of school-based and campus-based faculty to examine each course syllabus to determine how well the individual courses are integrated into a program of study.

3. We ask graduate student interns and Professional Practice School faculty members who serve as mentors to evaluate the degree of fit between campus coursework requirements and the demands of the internship.

4. We survey all our graduates yearly to determine whether the knowledge and skills developed in the program actually prepare them for a career as a teacher of children with disabilities. This survey is sent to graduates one year after they have completed the program.

In addition to these efforts, we have developed a complex cycle of feedback and feed-forward as an important part of our continuous evaluation efforts. For example, prior to the start of spring quarter 1996, mentor teachers and campus faculty will meet to share course requirements and discuss internship responsibilities such as writing IEPs. Possibly, campus-based faculty will modify course requirements to provide clearer coordination across the courses and a better fit to the internship requirements. Various groups, especially the mentor teachers, provide information about the program's impact on Professional Practice Schools-that is, impact in terms of the professional development of teachers and impact on learners in the school settings. Program and 
school coordinators also meet bimonthly to problem-solve other cross-program issues as they emerge.

The Teacher Education Council, composed of education, arts and sciences, and school representatives, ensures program fidelity to the pattern language and consistency in program and course delivery despite changes in the faculty. Each course is submitted to three cycles of review before it is taught. All courses have a portfolio housing student work, student and faculty evaluations, and a narrative including rationales and a participant list of the course's evolution.

We now are moving into an outcome evaluation phase. Several faculty members have undertaken studies of our efforts to date, and most recently the college provided $\$ 10,000$ to support groups of faculty conducting research on their teaching practices. This money facilitated the development and implementation of 10 studies. The college also is supporting a forum in which the findings from these projects will be shared. Our future challenge is to find ways to systematize and sustain our evaluation efforts.

\section{CLOSING THOUGHTS}

Now that we are seasoned travelers, we sometimes look back to where we have been, where we are now, and where we are going. Though our program still has many challenges to meet, we sometimes reflect on the beginning of our journey and feel proud of our accomplishments. When we began the process of redesign and reform, we did not anticipate accurately the time and energy needed, nor did we anticipate the many positive outcomes of our work. Some experiences have modified our initial expectations, and we realize that much work is yet to be done before our ideals, derived from our guiding principles, will be realized. We also believe that our program reform efforts could not have happened without the parallel collegewide reform. The design principles and the use of the pattern language gave the Special Education Program faculty guidance and support for the dramatic changes we made in our program.

We have a better idea about our destination now, though we always are interested in information about other people's journeys through program reform efforts that might provide us with interesting side trips or detours. We now know how to communicate better about our eventual destination and to talk with others we encounter on our journey. We are more comfortable with the detours that result from new ideas, from new administrative structures, and from new traveling companions. We continue to embark on these explorations into uncharted territory. For many of us, this has become both exciting and rewarding.

\section{REFERENCES}

Alexander, C., Ishikawa, S., \& Silverstein, M., (1977). A pattern language New York: Oxford University Press.

Alexander, C., Silverstein, M., Shlomo, A., Ishikawa, S., \& Abrams, D. (1975). The Oregon experiment. New York: Oxford University Press.

American Federation of Teachers (1988). Professional practice schools Building a model. Washington, DC: AFT

Bronfenbrenner, U. (1977). Toward an experimental ecology of human development. American Psychologist, 32, 513-531.

Holmes Group (1990). Tomorrow's schools: Principles for the design of professional development schools. E. Lansing, MI: The Holmes Group.

Holmes Group (1985). Tomorrow's schools of education. E. Lansing, MI: The Holmes Group.

Holmes Group (1995). Tomorrow's schools of education: A report of the Holmès Group. East Lansing, MI: Holmes Group.

Kurdek, L. A. (1981). An integrative perspective on children's divorce adjustment. American Psychologist, 36, 856-866.

National Commission on Excellence in Education. (1983). A nation at risk: The imperative for educational reform. Washington, DC: U.S. Government Printing Office.

National Science Foundation. (1983). Educating Americans for the 21st century: A report to the American people and the national science board. Washington, DC: Author.

Shulman, L. (1995). What is your vision for the field of educational research and for AERA in the twenty-first century? Panel discussion at annual meeting of American Educational Research Association, San Francisco, April 19.

Teitel, L. (1994). Can school-university partnerships lead to the simultaneous renewal of schools and teacher education? Journal of Teacher Education, 45(4), 245-252.

University of Cincinnati, College of Education, Holmes Planning Task Force. Progress report, Oct. 22, 1987.

Wong, M. J., \& Osguthorpe, R. T. (1993). Continuing domination of the four-year teacher education program: A national survey. Journal of Teacher Education, 44(1), 64-70.

Yinger, R. J. (1992). A pattern language for teaching. University of Cincinnati: Author.

\section{Note}

1. The Holmes Group-now the Holmes Partnership-works to improve education by designing a new curriculum; developing a university faculty that works well in public schools; recruiting and retaining a more diverse student body; creating professional development schools (new locations for all educational partners' work); and building networks at the local, state, and national levels (Holmes Group, 1995, pp. 2-3). The degree of success these institutions have achieved is difficult to determine because serious reform work entails changing the organizational cultures of two or more institutions. Gains made can disappear with changes in personnel and funding.

Ten years after the most recent wave of calls for education reform (such as A Nation at Risk in 1983; Action for Excellence in 1983; America's Competitive in 1983; Educating Americans for the 21st Century in 1983; and Educational Reform in 1983), Wong and Osguthorpe (1993) published a survey revealing the continued domination of 4-year, undergraduate teacher education programs. Researchers are cautious at best in predicting the endurance of professional development schools (Teitel, 1994; Shulman, 1995). 